\title{
Medical examiners: Independent or ignorant?
}

\author{
Ellen N Thompson MB BS FRCP
}

$\mathrm{T}$ he medicolegal conditions in Colorado before the changes introduced in 1997, as described in the article by Rossie and Gretzinger in this issue of Pain Research \& Management (pages 9-10), still exist in Canada and elsewhere. So-called independent medical examiners (IMEs) paid by the insurance companies repeatedly testify that injured motorists complaining of persistent pain and dysfunction have no real organic basis for their complaints and that they are fit to return to work. These experts are from various specialties but are frequently orthopedic surgeons, neurosurgeons, neurologists, physiatrists and psychiatrists. Psychologists and some manual therapists are also involved. Most appear genuine in their beliefs that there is nothing wrong with these patients. This is not surprising because actual knowledge about the pathophysiology of chronic pain is not a requirement to qualify as an expert in these matters.

The field of pain and its management, and knowledge of the pathophysiological processes causing it have reached a high degree of scientific sophistication built on a great deal of solid data. The two major texts on chronic pain $(1,2)$ individually outweigh pound for pound Harrison's Textbook on Internal Medicine, yet most IMEs encountered here appear to be unaware of the existence of these texts. Chronic pain is the one field where genuine ignorance is not a problem for the practitioner. Any demonstrated knowledge tends to be outdated, eg, Waddell et al's (3) nonorganic signs and Ransford et al's (4) pain drawings - all supposedly findings of nonorganic, ie, noncompensable pain - are frequently cited. It has long been observed and is increasingly understood, however, that such findings are to be expected in various neuropathic pain states $(5,6)$.

Because these examiners disbelieve the patients who they are asked to see, the encounters are frequently distressing to patients, who often feel degraded and abused. Discourteous and needlessly painful physical examinations are frequently experienced, and a high number of complaints to Colleges ensue, although many patients are often too crushed and too weary of medicolegal matters to lodge their legitimate complaints.

The reasons for the current status should be sought and understood. First, an observed increase in the incidence of 'whiplash' type pain and disability is said to have occurred over the past two to three decades - similar in size to increases in other conditions such as asthma and low back pain. There is some indication that the introduction of seat belts, while reducing head injuries, may have contributed to the increase in whiplash injuries; in addition, the growth in traffic may also have contributed to the increase in whiplash injuries (7). Second, abuse of the system by 'arranged' collisions appears to have occurred; seats in cars to be rear-ended were apparently for sale on the streets of Toronto at one time. The extent of this practice is not known. Third, attempts by legislators to limit costs while protecting motorists resulted in 'no fault' type systems. In 1994 in Ontario, insurance companies were mandated to provide and fund rehabilitation for three years (Bill 164), and in 1996 (Bill 59) for two years. The medical profession was unprepared to take on this task. Overnight, a new industry (modelled on the American systems) sprang up - the case management industry. Individuals operating and running these companies had, as a rule, no knowledge of pain medicine or rehabilitation, nor much other relevant data. They were frequently allied health care professionals - psychologists, former nurses or social workers. A great deal of nonindicated 'rehabilitation' ensued. Examples encountered include exercise training, which was provided via long distance telephone calls, and literacy training pro-

Anaesthesiology and Pain Management, Ottawa Hospital, Civic Campus, Ottawa, Ontario

Correspondence and reprints: Dr Ellen N Thompson, PO Box 546, Manotick, Ontario K4M 1A5. Telephone 613-761-4169, fax 613-761-5209,

e-mailnergard@aol.com 
vided to a male with post-traumatic headache so severe he refused to open his eyes. Thousands of dollars were billed for such services.

Because $80 \%$ of all injured motorists can be expected to recover substantially without therapy (by subtraction of numbers from references 8,9), a considerable number of them were subjected to 'rehabilitation' needlessly. A few cases were seen where physical therapies that repeatedly and consistently produced marked increases in levels of pain were administered in the mistaken belief that they would hasten recovery, when, in fact, it is a recipe for producing chronic pain (as used in laboratory experiments to create animal models of chronic pain).

It is, therefore, not correct to blame the insurance industry alone (or lawyers) for the current mess. The medical profession must shoulder much of the blame for the failure to incorporate scientific data regarding persistent pain and dysfunction into the diagnosis and proper management of individuals at risk for chronic pain from soft tissue injuries. It appears likely that about $20 \%(8,9)$ of the population is at increased risk for long term pain after trauma. If clinical research to identify these individuals were to be undertaken, allowing optimal therapy to be rendered, it is possible that material reduction of chronic problems could be achieved. The need for subjecting these individuals to the devastating process of IMEs and designated assessment centres (centres where IMEs and functional and vocational capacity assessments are carried out) would be greatly reduced, as would litigation. Both injured motorists and the insurance industry would be winners. Ignorant medical therapists and examiners would be the losers.

While these changes are likely to take some time to be achieved, the changes introduced in Colorado should be a step toward reducing cost, stress and abuse.

\section{REFERENCES}

1. Bonica JJ, ed. The Management of Pain. Philadelphia: Lea and Febiger, 1992.

2. Wall PD, Melzack R, eds. Textbook of Pain, 4th edn. Edinburgh: Churchill Livingstone, 1999.

3. Waddell G, McCulloch JA, Kummel E, Venner RM. Nonorganic physical signs of low back pain. Spine 1980;5:117-25.

4. Ransford AO, Cairns D, Mooney V. The pain drawing as an aid to the psychological evaluation of patients with low back pain. Spine 1976;1:127-34.

5. Ginzberg BM, Merskey H, Lau CL. The relationship between pain drawings and the psychological state. Pain 1988;35:141-6.

6. Tunks E. Pain arising from psychological causes. In: Vecchiet L, Albe-Fessard D, Lindblom U, eds. New Trends in Referred Pain and Hyperalgesia. Amsterdam: Elsevier Press, 1993:369-77.

7. Allen MJ, Barnes MR, Bodinala GG. The effect of seatbelt legislation on injuries sustained by car occupants. Injury 1985;16:471-6.

8. Buskila D, Neumann L, Vaisberg G, Alkalay D, Wolfe F. Increased rates of fibromyalgia following cervical spine injury. A controlled study of 161 cases of traumatic injury. Arthritis Rheum 1997;40:446-52.

9. Radanov BP, Sturzenegger M, DeStefano G, Schnidrig A. Relationship between early somatic, radiological, cognitive and psychosocial findings and outcome during a one-year follow-up in 117 patients suffering from common whiplash. Br J Rheumatol 1994;33:442-8.

\section{INDUSTRY NEWS}

\section{SCHERING CANADA ANNOUNCES MARKETING APPROVAL FOR TREATMENT OF ADVANCED OVARIAN CANCER}

Schering Canada has announced that CAELYX (pegylated liposomal doxorubicin hydrochloride injection) has been approved by the Therapeutic Products Programme (TPP) of Health Canada for the treatment of advanced ovarian carcinoma that has failed to respond to standard first-line therapy (Platinum- and paclitaxel-based chemotherapy).

A pivotal, randomized, phase III, multicentre comparative clinical trial comprising 474 patients was conducted in the United States, Europe and Canada - 239 were randomly assigned to receive CAELYX, and 235 to receive topotecan. CAELYX $50 \mathrm{mg} / \mathrm{m}^{2}$ was given as a $1 \mathrm{~h}$ infusion once every four weeks and topotecan $1.5 \mathrm{mg} / \mathrm{m}^{2} /$ day was given as a $30 \mathrm{~min}$ infusion daily for five consecutive days every three weeks. CAELYX demonstrated survival, toxicity and quality of life benefits for patients with advanced ovarian carcinoma that failed to respond to first-line treatment with combination platinum/paclitaxel.

The main dose-limiting toxicity with CAELYX was palmarplantar erythrodysesthesia (PPE), or the hand-foot syndrome, which occurred in $49 \%$ of patients receiving CAELYX $-23 \%$ of which were grade 3 and grade 4 . However, few patients withdrew from treatment with CAELYX because of PPE, and most patients were managed by dose reductions and delays as needed.

This is the second indication approved in Canada for CAELYX, which is currently marketed for the treatment of AIDS-related Kaposi's sarcoma.

\section{MOUNT SINAI HOSPITAL PROVIDES UNIQUE TREATMENT RESOURCES TO PEOPLE WITH CHRONIC PELVIC PAIN}

Ontario's first multidisciplinary Chronic Pelvic Region Pain Unit opened in January at Mount Sinai Hospital, Toronto. The clinic was funded in part through a new partnership with Pharmacia Canada, and will provide a 'pain-focused' approach to disorders that are otherwise often underdiagnosed, misdiagnosed or poorly treated.

Studies report that $50 \%$ to $70 \%$ of women experience pelvic pain during intercourse at some point in their lives. More than $15 \%$ of women suffer from a form of chronic pelvic region pain that often goes undiagnosed. These conditions include persistent and severe menstrual and midcycle pain, endometriosis, vulvar pain syndromes, cystitis syndromes, pelvic muscle pain syndromes and pain from nerve entrapment. Dr Allan Gordon, Director of the Wasser Pain Management Centre says, "Chronic pelvic region pain is a serious goup of disorders that affects many women. To properly treat pain, we need to take a multidisciplinary approach that includes not just gynecologists but other disciplines, bringing together neurologists and other pain specialists from nursing, urogynecology, acupuncture, clinical neurophysiology, physical therapy and mental health services".

The Chronic Pelvic Region Pain Unit is situated in a teaching hospital, and patients will have access to a wide range of services through the Wasser Pain Management Centre. 


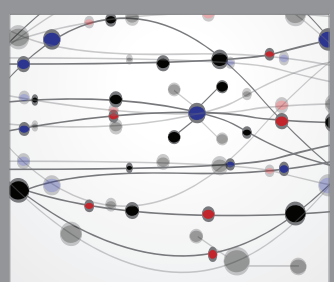

The Scientific World Journal
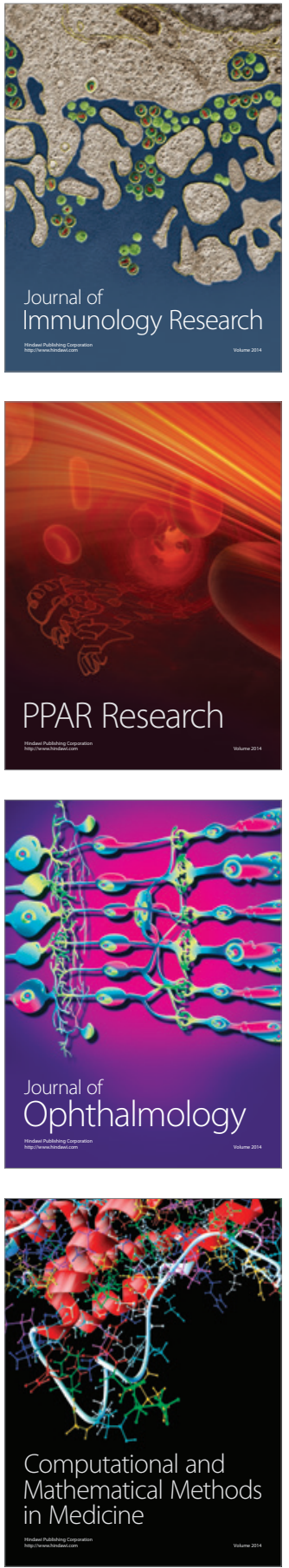

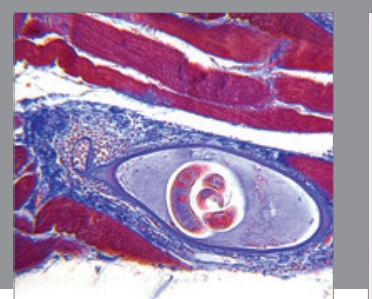

Gastroenterology Research and Practice

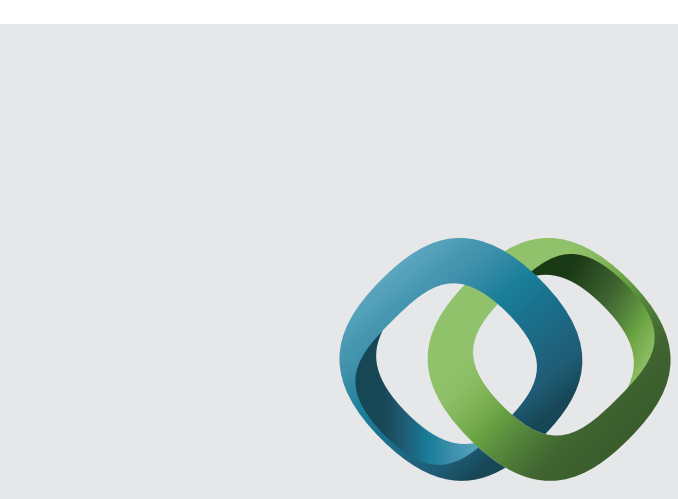

\section{Hindawi}

Submit your manuscripts at

http://www.hindawi.com
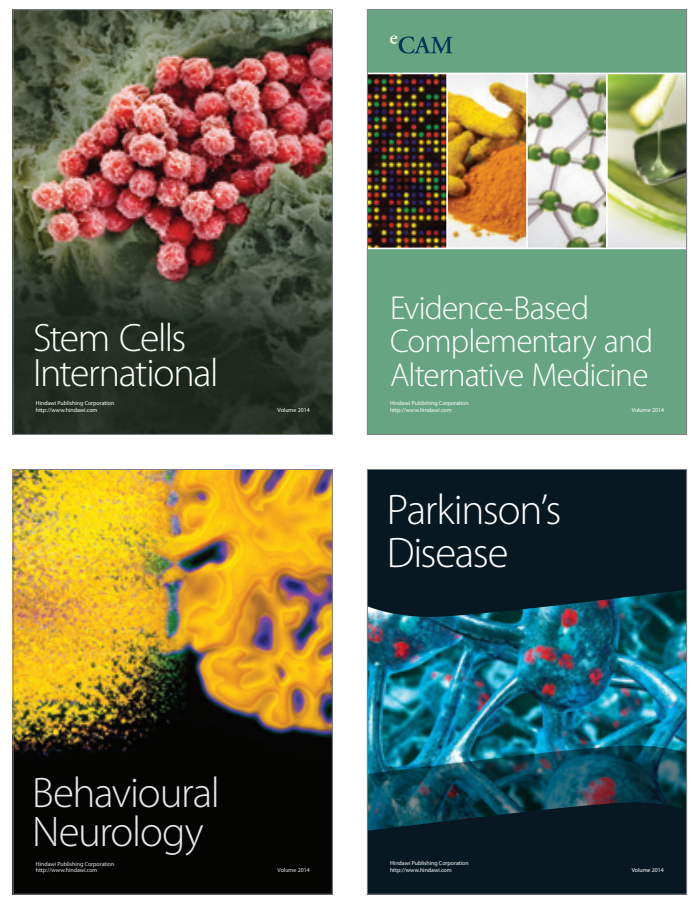
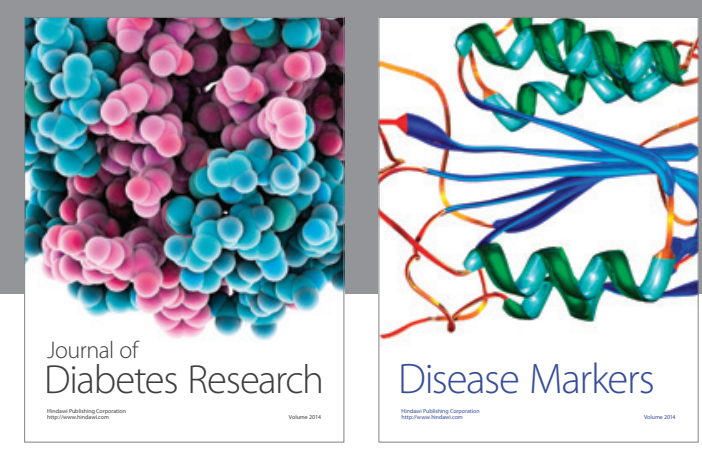

Disease Markers
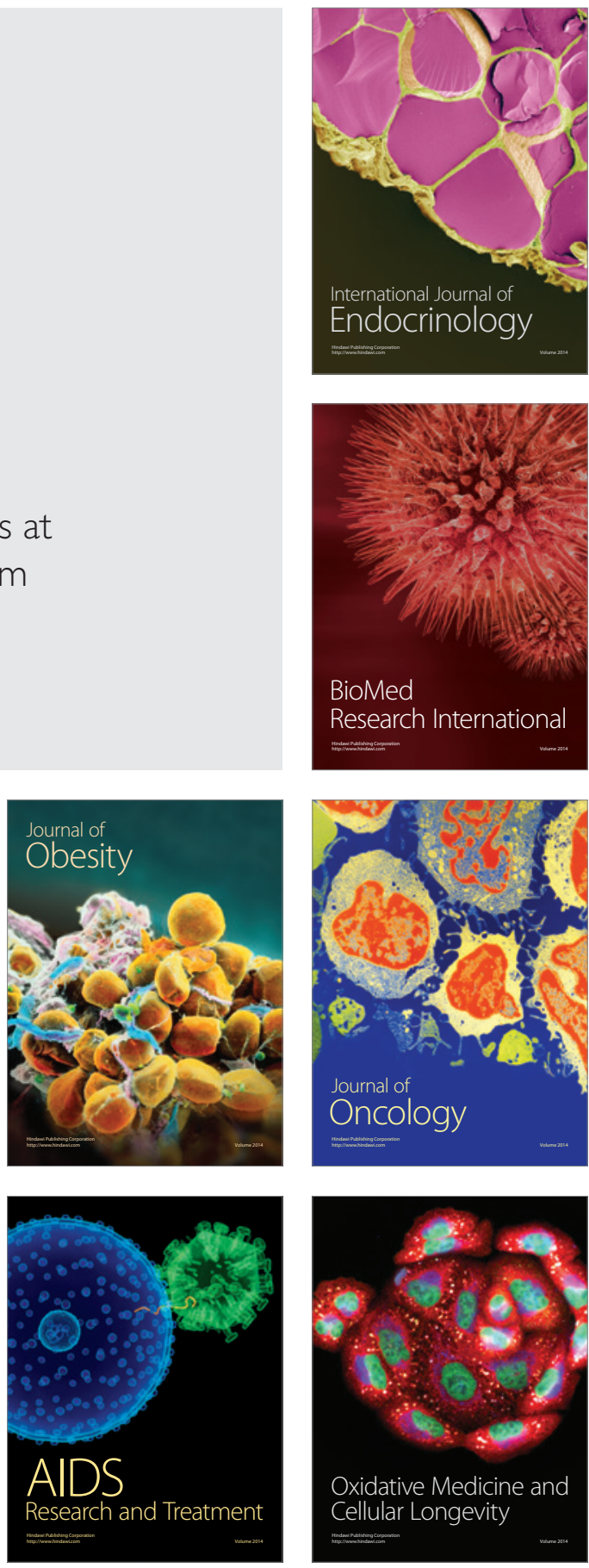